\title{
Correction to: Preserving Lysosomal Function in the Aging Brain: Insights from Neurodegeneration
}

\section{Wesley Peng ${ }^{1} \cdot$ Georgia Minakaki $^{1} \cdot$ Maria Nguyen $^{1} \cdot$ Dimitri Krainc $^{1}$}

Published online: 24 July 2019

(C) The American Society for Experimental NeuroTherapeutics, Inc. 2019

\section{Correction to: Neurotherapeutics} https://doi.org/10.1007/s13311-019-00742-3

This article was corrected to include a revised version of figure 2 overlooked by the Publisher during the production process.

The online version of the original article can be found at https://oi.org/ 10.1007/s13311-019-00742-3

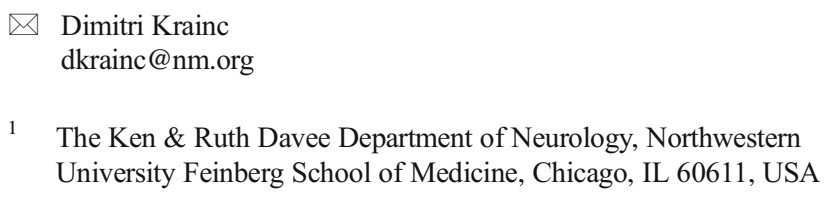




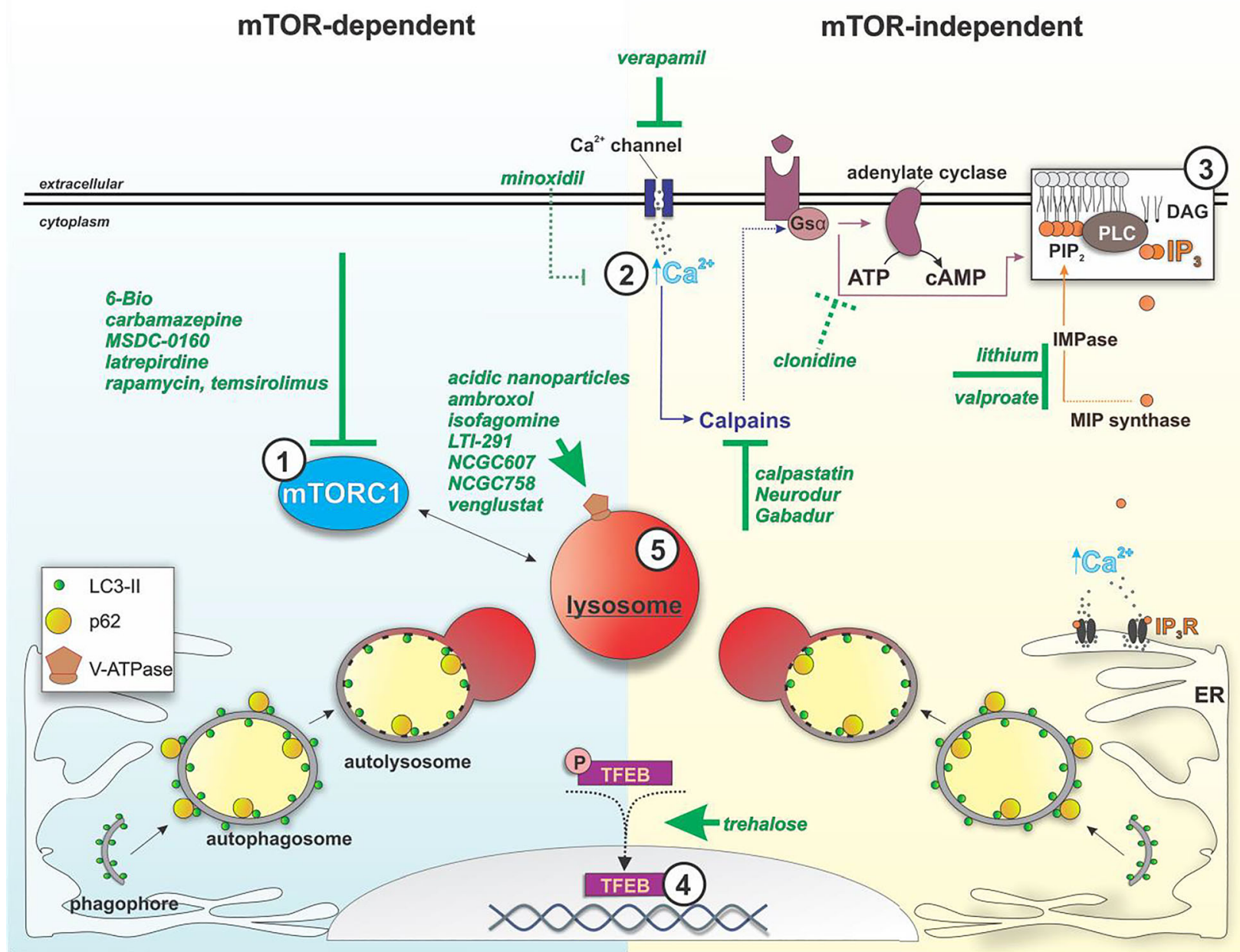

Publisher's Note Springer Nature remains neutral with regard to jurisdictional claims in published maps and institutional affiliations. 